\title{
CONTRIBUIÇÕES DO PIBID NA CONSTRUÇÃO DO PERFIL REFLEXIVO- CRÍTICO DE PROFESSORES DE CIÊNCIAS
}

\section{EMERSON NUNES DA COSTA GONÇALVES}

\author{
Secretaria de Estado da Educação do Espírito Santo \\ E-mail: e193196@dac.unicamp.br
}

\section{MICHELE WALTZ COMARÚ}

Instituto Federal do Espírito Santo

E-mail: mcomaru@ifes.edu.br

\section{RESUMO:}

O objetivo deste trabalho foi investigar as contribuições do Pibid na formação inicial de professores de Ciências Naturais. Tratou-se de uma pesquisa qualitativa sobre a relação dos pibidianos com a carreira docente e as possíveis contribuições deste programa na sua formação profissional. Os dados foram produzidos a partir de observações, entrevistas e análise de documentos oficiais, considerando a participação no programa entre os anos de 2010 e 2013, originados do campus de São Mateus da UFES. Os resultados indicaram que os discentes não eram esclarecidos quanto às características da licenciatura na ocasião do ingresso e tampouco da identidade e práticas do professor de Ciências Naturais. Porém, a experiência critico-reflexiva da prática pedagógica e da carreira docente durante sua participação no programa desmistificou as crenças e mitos sobre a educação pública, o que promoveu a construção de conceitos e interesses sobre a docência e contribuiu na formação inicial desses futuros professores da educação básica.

\section{PALAVRAS-CHAVE:}

Pibid, formação inicial de professores, professores de ciências naturais.

\section{Brazillian Teaching Education Program Contribution to the Construction of the SCIEnCE TEACHER'S CRITICAL REFLEXIVE ROLE}

\section{ABSTRACT:}

This is a qualitative research, about how Brazillian Teaching Education Program (in Portuguese Pibid) contributes to the initial formation of science teachers. Seven scholars were interviewed and through discursive textual analysis, categories of analysis were identified and propositions for discussions about their relation to a teaching career and as contributions of Pibid to their formation during the participation in the program between the years of 2010 and 2013. It was revealed that the discourses are not completely clarified as to the characteristics of the degree upon admission, nor of the identity of the science teacher and of his practice, but a reflexivecritical experience about a pedagogical practice and teaching career during his participation in the 


\section{D|EDebates

Pibid, demystified taboos on public education, building concepts and interests on teaching, contributing to the initial training of future teachers of basic education sciences.

\section{KEYWORDS:}

Pibid, initial teacher training, science teachers.

\section{INTRODUÇÃO}

Durante as últimas três décadas, tem-se intensificado as discussões sobre as práticas de ensino de Ciências no Brasil, para além daquelas voltadas para a formação tecnicista presentes nos anos de 1960 até o final dos anos de 1970 (NASCIMENTO; FERNANES; MENDONÇA, 2010), surgindo outros olhares e posturas na maneira de se ensinar ciência em relação às práticas tradicionais, uma conquista advinda e evidente, principalmente, a partir da década de 1980 pelo surgimento de questionamentos que envolviam uma proposta crítica acerca dos rumos que o mundo tomava no âmbito da ciência e da tecnologia, pelos diversos acontecimentos sociais, políticos e econômicos, "sintomas da grave crise econômica mundial" do pós-guerra, numa proposta voltada para "Ciência, Tecnologia e Sociedade", em paralelo à Educação Libertadora e à Pedagogia Crítico-Social dos Conteúdos, tendências progressistas da educação (BRASIL, 1998).

Desse contexto histórico implica que na virada da década de 1980 para a de 1990 ocorre, segundo Pereira (2007), uma "crise de paradigmas" tanto nas Ciências Sociais, e principalmente na Educação, abrindo espaço, então, para estudos sobre a formação do docente num aspecto que ele denomina de "agente-sujeito", num novo cenário que vai privilegiar a formação do professor-pesquisador, "aquele que pensana-ação, o profissional reflexivo" (Idem, 2007, p. 41), o que é reforçado por Alarcão (1996) nas análises que faz dos trabalhos de Schön (2000).

Nas novas perspectivas de como ensinar sobre ciência, Astolfi e Develay (2012) nos apresentam que a formação docente está baseada no domínio dos saberes 


\section{D|EDebates

acadêmicos e profissionais dos professores, o que influirá de forma positiva no sucesso escolar dos discentes e nos chamam a atenção, comentando sobre as especificidades da docência, que "[...] é antes de tudo uma profissão de tomada de decisão em sistemas complexos onde interagem inúmeras variáveis das quais o professor faz parte" (Idem, 2012, p.122).

Deve-se, então, os professores, valorizarem as representações dos estudantes, considerando uma reflexão epistemológica a respeito dos conteúdos abordados, integrando uma história das ideias com a exposição de saberes, justificando o que eles consideram como saberes profissionais (ASTOLFI; DEVELAY, 2012).

Essas colocações nos instigaram a algumas questões que cerceiam a formação do futuro professor de Ciências dos Anos Finais (AF) do Ensino Fundamental (EF), o licenciando em Ciências Biológicas, frente às políticas de formação inicial de professores, indagando-nos sobre: Como estão inseridos os discentes dos cursos de licenciatura plena em Ciências Biológicas nos contextos das escolas públicas brasileiras? Estão inseridos? Que oportunidades esses cursos de formação inicial oferecem aos futuros professores de Ciências em apropriações e ressignificações quanto aos saberes produzidos no "chão da escola"? Quais são as representações que esses estudantes trazem sobre a educação pública e mais especificamente sobre o ensino de Ciências?

Sobre as políticas públicas para formação inicial de professores, surge no ano de 2007 o Programa de Bolsa Institucional de Iniciação à Docência - Pibid, que de acordo com Gonçalves e Comarú (2015), apresentou-se inovador quanto à oferta de bolsas específicas para discentes de licenciatura“[...] não constando na história da educação brasileira algo antes parecido, sendo que os alunos desses cursos geralmente estariam cadastrados em programas de iniciação científica e que não 
valorizavam suas respectivas áreas de formação pedagógica" (GONÇALVES; COMARÚ, 2015, p. 2).

Estendemos, então, essa discussão, problematizando a formação dos futuros professores de Ciências dos Anos Finais do Ensino Fundamental no contexto do Pibid-Biologia da Universidade Federal do Espírito Santo, intentando sobre clarificações que nos permitiram entender como esse Programa é capaz de colaborar na construção do perfil reflexivo e crítico de discentes, bolsistas participantes do Programa, quanto à carreira docente.

O objetivo deste trabalho foi o de investigar as contribuições do Pibid na formação inicial de professores de Ciências Naturais. Tratou-se de uma pesquisa qualitativa sobre a relação dos pibidianos com a carreira docente e as possíveis contribuições deste programa na sua formação profissional. Os dados foram produzidos a partir de observações, entrevistas e análise de documentos oficiais, considerando a participação no programa entre os anos de 2010 e 2013, originados do campus de São Mateus da UFES.

\section{FUNDAMENTOS}

Para melhor nos situarmos na investigação desenvolvida, apresentamos, nos próximos dois tópicos desse artigo, uma reflexão sobre a legislação que ampara o Pibid e sua implantação na Ufes.

\subsection{SOBRE O PIBID: ENTENDIMENTOS LEGAIS E REFLEXÕES}

O Programa de Bolsa Institucional de Iniciação à Docência - Pibid, foi criado pela Portaria Normativa N. 38 , de dezembro de 2007, numa parceria entre 0 Ministério da Educação, a Secretaria de Educação Superior (SESU), a Coordenação de Aperfeiçoamento de Pessoal de Nível Superior (CAPES) e o Fundo Nacional de Desenvolvimento da Educação (FNDE), com o intuito inicial, como consta no artigo 
1 o desse documento, de "[...] fomentar a iniciação à docência de estudantes das instituições federais de educação superior e preparar a formação de docentes em nível superior, em curso presencial de licenciatura de graduação plena, para atuar na educação básica pública" (BRASIL, 2007).

Até o primeiro semestre de 2016, a portaria № 96 de julho de 2013, era o documento referencial que definia os critérios, normas e regras do Pibid, revogando a Portaria N.ㅇ 260, de 30 de dezembro de 2010, que cumpria com essa obrigação. Ela definia o Pibid como um programa da CAPES, reafirmando sua função, declarada na Portaria Normativa N. ${ }^{\circ}$ de 38 , de dezembro de 2007, de fomentar a iniciação à docência, contribuindo para o aperfeiçoamento da formação de docentes em nível superior e a melhoria da qualidade da Educação Básica pública brasileira. Deixava também mais clara, as prerrogativas do Programa, caracterizando as relações que podem ser evidenciadas entre os atores que estarão envolvidos nesse processo de formação e que tem o Pibid, apresentando, dentre outros, o objetivo de "[...] contribuir para que os estudantes de licenciatura se insiram na cultura escolar do magistério, por meio da apropriação e da reflexão sobre instrumentos, saberes e peculiaridades do trabalho docente" como descrito no Artigo 4으, inciso VII, dessa portaria (BRASIL, 2013).

Atualmente, a Portaria N.o 46 de 11 de Abril de 2016, é o instrumento legal que aprova e regulamenta o Pibid, numa outra versão, agora, com prerrogativas que reestabelecem seu caráter formativo, algo que se constata claramente no parágrafo II do artigo 70, quando esse diz que a articulação das instituições envolvidas deve contemplar a [...] articulação com os programas institucionais do MEC, tais como o Programa Nacional de Alfabetização na Idade Certa - Pnaic, Programa Mais Educação - PME, Programa Ensino Médio Inovador - Proemi e Pacto pelo Fortalecimento do Ensino Médio - PNEM (BRASIL, 2016). 


\section{D|EDebates

Desse contexto, vale refletirmos sobre as adequações dos objetivos traçados desde o início do Programa, na sua primeira versão, a partir da análise que se faz do exposto acima. Identifica-se, no vigor da Portaria N. ${ }^{\circ} 96$, a maior preocupação com a participação das escolas onde os projetos seriam implantados na formação do futuro professor, solicitando dos seus professores serem coparticipantes do processo de formação dos licenciandos bolsistas, dando-lhe um caráter coeso e colaborativo.

Porém, nota-se que num documento anterior, a Portaria Normativa N.․72, de 09 de abril de 2010, que dava nova redação à Portaria N. ${ }^{\circ} 38$, no inciso segundo do artigo primeiro, dentre outros, o seguinte objetivo:

IV) proporcionar aos futuros professores participação em experiências metodológicas, tecnológicas e práticas docentes de caráter inovador e interdisciplinar e que busquem a superação de problemas identificados no processo de ensino-aprendizagem, levando em consideração o desempenho da escola em avaliações nacionais, como Provinha Brasil, Prova Brasil, SAEB, ENEM, entre outras (BRASIL, 2010).

Notamos, nesse fragmento, uma preocupação com os índices de desempenho apresentados pelas escolas, alcançados nas avaliações aplicadas pelo Ministério da Educação (MEC), atrelando a inserção dos bolsistas na escola como uma prerrogativa de melhoria desses resultados, o que nos cabe uma análise crítica dessa intenção, considerando se o Pibid deva ter esse caráter ou se, também, possa levar aos melhores resultados de desempenho, de acordo com cada realidade de execução.

Porém, não é identificado na Portaria N. 96, qualquer menção a isso, deixando implícito essa intenção no item IV do artigo quarto, desse documento, quando se diz "[...] práticas docentes de caráter inovador e interdisciplinar que busquem a superação de problemas identificados no processo de ensinoaprendizagem" (BRASIL, 2013), algo nitidamente resgatado no novo formato do Pibid em vigor, pela Portaria N. ${ }^{\circ} 46$ de 2016, caracterizando-se, agora, como um Programa de caráter impositivo, radical e sem flexibilidades construtivas de uma proposta 
emancipadora de formação desses futuros professores, como solicitado por Freire (2006; 2007), quando suas principais diretrizes estão ligadas à melhoria dos índices dos alunos da Educação Básica nas avaliações externas.

Pelas constatações descritas, entendemos que a desenvoltura e notoriedade do Pibid, quanto ao processo de formação inicial de professores, possui grande potencial de pesquisa dentre outras peculiaridades por:

[...] ter se demonstrado no primeiro momento da sua implementação junto aos subprojetos nas universidades e nas escolas básicas como um desafio de integração entre os atores que dele participam quanto às práticas que devem promover como um Programa eficiente na colaboração da formação diferenciada dos licenciandos vinculados a ele. (GONÇALVES; COMARU, 2015)

Dentre as experiências proporcionadas pelo (Pibid), destacamos a adesão da UFES, no campus São Mateus, no Centro Universitário Norte do Espírito Santo CEUNES, com a implantação do subprojeto Pibid-biologia, no ano de 2010, alvo dessa investigação, justificando-a pelas peculiaridades quanto às experiências desse subprojeto num período que era, ainda, de descobertas na fomentação do Pibidbiologia pela primeira vez no Centro Universitário Norte do Espírito Santo (CEUNESUfes), a partir de uma prática colaborativa entre os sujeitos participantes desse processo - professores coordenadores, pibidianos e professores supervisores.

\subsection{A IMPLANTAÇÃO DO PIBID NA UFES}

A participação Ufes, no Pibid, acontece desde o primeiro edital de oferta do Programa, em 2007 (BRASIL, 2007b), pela CAPES, vigente até fevereiro de 2011, o que envolveu 5 pesquisadores dessa Universidade das áreas de Educação e das Ciências da Natureza, Matemática, Física, Química e Biologia, 8 professores da rede 
pública estadual e 72 licenciandos dessas áreas, inseridos nas escolas públicas de maior porte na região metropolitana (SILVA, 2009).

Para Silva (2009, p. 07) mesmo que a equipe estivesse afinada quanto aos objetivos do Programa, foi difícil estabelecer as bases iniciais de coletividade de algumas prerrogativas como as práticas a serem implementadas, a definição de prioridades, cronogramas e planejamentos conjuntos, por exemplo.

Na voz dessa autora,

Faltava aos professores da universidade a familiaridade com os ritos, tempos e espaços escolares. A rigidez dos horários, as delicadas relações interpessoais, o número elevado de alunos nas escolas, a falta de recursos materiais e tantas outras dificuldades desafiavam os planejamentos e exigiam constantes remanejamentos de rota. [...] Podemos dizer que o estabelecimento das relações foi a maior ênfase da fase inicial de implementação do projeto. Era preciso colocá-lo em andamento. Vieram os primeiros conflitos, mas também as primeiras conquistas. Aos poucos, começamos a constatar o que há muito já sabíamos: que a relação Universidade-Escola é possível, viável e muito enriquecedora. Temos visto nossos licenciandos, antes desmotivados em relação à carreira docente, explicitarem seu entusiasmo e confiança diante das manifestações de receptividade das escolas. Temos visto os professores das escolas adquirirem um novo ânimo. Temos aprendido a incorporar aos programas de curso das licenciaturas as questões advindas do cotidiano escolar e do currículo vivido. (SILVA, p. 08-09)

Para a professora Dr. a Mirian do Amaral Jonis Silva ${ }^{1}$, desde a sua implementação, em 2008, é constatado uma redução significativa da evasão nos cursos de licenciatura, vislumbrando-se que identidade profissional docente, visando

\footnotetext{
${ }^{1}$ Dr.a Mirian do Amaral Jonis Silva, é professora do Centro de Educação da Universidade Federal do Espírito Santo, e respondeu desde a implantação do PIBID como coordenadora geral do Programa na instituição, sendo essa fala realizada no I Encontro de PIBID da UFES, em 17 de Novembro de 2013, que reuniu três Centros onde são desenvolvidos os subprojetos do PIBID em Vitória, São Mateus e Alegre. A fala da professora é encontrada na íntegra no site de comunicação da UFES, que relata o evento: portal.ufes.br/conteudo/ufes-realiza-i-seminário-do-programa-de-bolsas-de-iniciação-à-docência.
} 
à construção de ações conjuntas que proporcionem práticas inovadoras no ensino na escola básica a partir de uma recíproca respeitosa com essas instituições.

No ano de 2014 existiam cerca de 50 mil bolsas distribuídas para todo o país, sendo que na UFES, o Programa se estendia, nesse período, pelos cursos de licenciatura de Artes Plásticas e Visuais (01 subprojeto), Biologia (03 subprojetos), Ciências Sociais (01 subprojeto), Educação Física (01 subprojeto), Filosofia (01 subprojeto), Física (03 subprojetos), Geografia (01 subprojeto), História (01 subprojeto), Letras (01 subprojeto), Matemática (03 subprojetos), Música (01 subprojeto), Pedagogia (01 subprojeto), Química (03 subprojetos), além de dois subprojetos interdisciplinares, nos campi de Vitória, São Mateus e Alegre, envolvendo docentes da Universidade, docentes das redes públicas de ensino estadual e das redes municipais de desses municípios - Alegre e São Mateus, com um número total de 574 participantes no Programa, o que corresponderia à 463 bolsistas, 70 professores supervisores, 37 coordenadores de área e 4 coordenadores.

Para a implantação do Pibid em São Mateus, no CEUNES, a equipe organizadora do Subprojeto de Licenciatura em Ciências Biológicas teve como referência dados importantes sobre a questão das escolas no norte do Estado, definindo suas prerrogativas quanto à intenção de adesão ao Programa nessa instituição, constatando-se que:

[...] apesar de o Ensino Médio na atualidade ser de responsabilidade dos estados, ainda existe ocorrência na região de escolas municipais de Ensino Médio, merecendo referência o fato de que para um total de 815 escolas de Ensino Fundamental, só existem 67 escolas de Ensino Médio, menos de $10 \%$, significando que para uma relação de 133,32matriculados no Ensino Fundamental por escola, há uma relação de 408,82 matriculados no Ensino Médio por escola, considerando um total de 27.391 alunos matriculados no Ensino Médio em 2006. Outra comparação relevante, é que no Ensino Fundamental existe uma relação de 18,46 alunos por professor, enquanto que no Ensino Médio essa relação é de 19,11 alunos por professor. Assim 
pode-se concluir que o Ensino Médio do Norte capixaba pede ajuda. Ele necessita ser ampliado e as condições de ensino melhoradas. (ESPÍRITO SANTO, 2009).

Verificou-se com os números apontados, a justificativa de necessidade da implementação do Pibid na região, identificando que o Ensino Médio no norte do Espírito Santo, carecia de atenção. Isso foi reforçado, pelas origens do campus São Mateus, pelo Programa de Reestruturação e Expansão das Universidades Federais (REUNI) no Brasil, ressurgindo da sua antiga estrutura, o Polo Universitário Norte do Espírito Santo, agora com autonomia de Centro Universitário com contemplação de quatro cursosde licenciatura: Física, Matemática, Química e Biologia com início em 2010/1, no mesmo período em que foi lançado edital do Pibid aberto, Edital n. 02/2009 - CAPES/DEB, para esse Programa, dos alunos das licenciaturas identificando essa como

[...] uma condição ímpar de melhorar a qualidade do Ensino Médio na região, através da possibilidade e o incentivo aos alunos ingressantes nos cursos de licenciaturas de praticar atividades relativas à docência. (ESPÍRITO SANTO, 2009)

Reconhecermos a importância do Pibid como uma política de formação inicial dos futuros professores e, mais especificamente, dos professores de Ciências; na Educação Básica, nos instigaram aos seguintes questionamentos: O Pibid-Biolgia, no campus São Mateus, se apresentou como uma possibilidade de espaço reflexivo e crítico para os discentes licenciandos quanto às questões da carreira docente e o ensino de Ciências na Educação Básica?

Para as devidas clarificações na busca de respostas às questões levatantadas nos subsidiamos em autores como Nóva (2002), Zeichner (1993), Mizukami (2010) e Schon (1992) quanto a formação inicial do professor e a construção do perfil do professor reflexivo docente. 


\subsection{O PROFESSOR REFLEXIVO}

De acordo com Nóvoa (2002, p. 27), "não é fácil definir o conhecimento profissional", esclarecendo-nos sobre as diferentes dimensões que o cercam, prática e experiência, alegando que há um conjunto de saberes, competências e atitudes, na ação educativa, difícil de ser formalizada e conceituada, o que exige uma "[...] reflexão prática e deliberativa" (idem, p. 27).

Sobre essa condição reflexiva Zeichner (1993) nos chama a atenção de que seu significado está no

“[...] reconhecimento de que a produção de conhecimento sobre o que é um ensino de qualidade não é propriedade exclusiva das universidades e centros de investigação e desenvolvimento e de que os professores também têm teorias que podem contribuir para uma base codificada de conhecimentos do ensino" (ZEICHNER, 1993,p. 16).

Nessa condição, os formadores de professores devem, então, orientar os aprendizes de professores, na sua formação inicial a estarem disponíveis e capazes da sua forma de ensinar, melhorando com o tempo (ZEICHNER, 1993).

Numa análise sobre a formação inicial dos professores, Mizukami (2010) discorre sobre o contraponto que há entre a racionalidade técnica e a racionalidade prática da ação educativa, num jogo de conflitos entre a hierarquização superior do conhecimento teórico com validação científica em detrimento ao conhecimento prático, e, apoiada em Schön (1992), afirma que "superá-lo exige a superação da relação mecânica e linear entre o conhecimento científico e técnico e a prática concreta de sala de aula" (idem, p. 20).

Caracterizar o professor na sua constituição político pedagógico como um profissional reflexivo é uma postura que passa a tomar notoriedade no cenário educacional, que traz, segundo Pimenta (2002), o norte-americano Donald Schön, como seu principal formulador, no início dos anos de 1990, valorizando a filosofia de 
John Dewey da experiência e a reflexão na experiência, apresentado como conhecimento tácito, baseada no que se denominou epistemologia da prática, que é

[...] valorização da prática profissional como momento de construção de conhecimento, através da reflexão, análise e problematização desta, e o reconhecimento do conhecimento tácito, presente nas soluções que os profissionais encontram em ato (Idem, 2002, p. 19).

Compactuamos com Mizukami (2010) quando, ao citar Imbernón (2000), nos acrescenta que a formação inicial tem a função de fornecer os alicerces construtivos dos conhecimentos pedagógicos específicos, caracterizando-se "[...] no começo da socialização profissional e da assunção de princípios e regras praticas" (idem, p. 22), de forma interativa e dialética, com a criação de condições interventivas, cooperativas, em processo de análise, reflexão e investigação rigorosa (Imbernón, 2000, apud Mizukami, 2010).

Nesse sentido, essa pesquisa buscou entender que caminhos os cursos de licenciatura devem se propor ao pensarem a formação dos seus discentes, e que políticas de valorização do magistério devem ser planejadas para a motivação dessas futuras gerações de professores de Ciências em relação à carreira docente de forma lúcida quanto às proposições dos cursos de licenciatura, tendo como foco o Pibid.

\section{METODOLOGIA}

Essa foi uma pesquisa qualitativa, do tipo exploratória (LÜDKE; ANDRÉ, 1986; WELLER; PFAFF, 2011). Teve como sujeitos 07 licenciandos bolsistas do Pibid/UFES, do Centro Universitário Norte do Espírito Santo, atuantes nos períodos letivos dos anos de 2010 à 2013, numa escola pública estadual do estado do Espírito Santo, nos Anos Finais do Ensino Fundamental, denominados, para efeito de proteção das suas identidades, de Bolsista I (BI), Bolsista II (BII), Bolsista III (BIII), Bolsista IV (IV), Bolsista 


\section{D|EDebates

V (BV), Bolsista VI (BVI) e Bolsista VII (BVII), devidamente esclarecidos pelos pesquisadores dos seus direitos enquanto participantes da pesquisa. Utilizou-se como recurso metodológico a realização de entrevistas a partir de um questionário semi-estruturado, com registros videogravados (LÜDKE \& ANDRÉ, 1986; BELEI, 2013; DUARTE, 2004; MIGUEL, 2010).

Para a análise do material coletado nas entrevistas, utilizamos a análise textual discursiva que, segundo Moraes e Galiazzi (2013, p. 78), “[...] pode ser concebida a partir de dois momentos opostos e ao mesmo tempo complementares: o primeiro de desconstrução, de análise propriamente dita; o segundo reconstrutivo, um momento de síntese", de forma que há a construção básica da estrutura de metatextos, produzidos de dois processos iniciais, que são unitarização e categorização do corpus.

Cabe ressaltar que a unitarização corresponde ao recorte e fragmentação, reunidos a partir de diversas formas de coleta, ocorrendo por diferentes condições linguísticas, o que resultará em múltiplas unidades de análise (MORAES, 2003; MORAES \& GALIAZZI, 2006; MORAES \& GALIAZZI, 2013), enquanto a categorização nesse método de análise é um processo longo e exigente, correspondendo à um

[...] processo de criação, ordenado, organização e síntese. Constitui, ao mesmo tempo, processo de construção de compreensão dos fenômenos investigados, aliada à comunicação dessa compreensão dos fenômenos por meio de uma estrutura de categorias (MORAES; GALIAZZI, 2013, p. 78).

As entrevistas filmadas e transcritas compõem o corpus da investigação de onde foram elaborados metatextos, fruto da interpretação das expressões orais dos entrevistados pelos pesquisadores, buscando, sempre, manter o máximo de sigilo sobre suas identidades.

Das entrevistas transcritas foram obtidos metatextos, correspondentes às expressões videogravadas que demonstram dos pibidianos sua relação com a 
carreira docente e quais as implicações que o programa trouxe para a questão da formação.

\section{RESULTADOS E DISCUSSÃO}

Destacamos dos metatextos três categorias de análise, que nos motivaram às proposições de discussão, no que tange, as afinidades e interesses dos licenciandos pela carreira docente e os contextos por eles vivenciados nas escolas públicas durante sua formação do Ensino Básico, sua vivência como pibidianos e suas experiências com as atividades desenvolvidas no Programa, apresentadas no quadro 1.

Quadro 1. Categorias de análise e proposições de discussão obtidas dos metatextos construídos das entrevistas com os pibidianos. Fonte: Dados da Pesquisa.

\begin{tabular}{|c|c|}
\hline \multicolumn{2}{|c|}{ Categorias e Proposições de Análise } \\
\hline Categorias de Análise & Proposições de Discussão \\
\hline $\begin{array}{l}\text { i. Identificação dos sujeitos com as } \\
\text { Ciências Biológicas e o curso de } \\
\text { Licenciatura. }\end{array}$ & $\begin{array}{c}\text { Proposição I. Os licenciandos bolsistas do Pibid ingressam } \\
\text { nos cursos de licenciatura plena em Ciências Biológicas } \\
\text { por sua afinidade com a área das Ciências da Natureza, } \\
\text { porém, não entendendo o objetivo real do curso quanto } \\
\text { à formação de futuros professores de Ciências e Biologia } \\
\text { do Ensino Básico. }\end{array}$ \\
\hline $\begin{array}{l}\text { ii. As concepções dos sujeitos sobre a } \\
\text { escola de Ensino Básico público e o } \\
\text { perfil do professor de Ciências. }\end{array}$ & $\begin{array}{l}\text { Proposição II. Os licenciandos bolsistas não possuem boas } \\
\text { impressões sobre a escola de Ensino Básico pública e a } \\
\text { carreira docente, o que interfere diretamente no seu } \\
\text { interesse em atuarem como futuros professores do } \\
\text { Ensino Básico. }\end{array}$ \\
\hline iii. A vivência dos sujeitos no Pibid. & $\begin{array}{c}\text { Proposição III. O contato dos licenciandos em Ciências } \\
\text { Biológicas com o cotidiano das escolas de Ensino Básico, } \\
\text { no Pibid, promoveu implicações significativas sobre seu } \\
\text { processo de decisão quanto à carreira docente. }\end{array}$ \\
\hline
\end{tabular}




\section{E Debates

Como mencionado, a análise dos dados foi subsidiada por proposições que surgiram a partir das categorias de análise identificadas na construção dos metatextos, como apresentaremos a seguir:

Proposição I. Os licenciandos bolsistas do Pibid ingressam nos cursos de Licenciatura Plena em Ciências Biológicas por sua afinidade com a área das Ciências da Natureza, porém, não entendendo o objetivo real do curso quanto à formação de futuros professores de Ciências e Biologia do Ensino Básico.

Dentre os interesses nas entrevistas com esse grupo de licenciandos bolsistas, estava o de identificar quais as motivações que os levaram a ingressarem no curso de licenciatura plena em Ciências Biológicas e como elas estariam relacionadas aos objetivos desse curso de formar futuros professores de Ciências e Biologia para o Ensino Básico.

Percebemos que esse seria um caminho viável na identificação das implicações que o Pibid proporcionou a esses bolsistas, no que se refere ao objetivo traçado no estudo de caso proposto.

Identificamos que o interesse pelas Ciências da Natureza motivado pelo contato com seus conteúdos curriculares no Ensino Básico, bem como com professores das disciplinas curriculares Ciências e Biologia que foram capazes de promover significativamente esses conteúdos, foi algo determinante na escolha pelo curso de Biologia de alguns dos licenciandos bolsistas entrevistados. Evidenciamos isso no discurso do BI quando the foi perguntado "Você já pensou por que você escolheu o curso de Biologia como área de formação?", apresentando-nos como resposta: 
Quadro 2: Resposta do bolsista sobre a escolha da área de formação. Fonte: Dados da Pesquisa.

BI - [...] na verdade foi pela experiência que eu tive na infância, no Ensino Fundamental e Médio. No Ensino Médio foi mais pelos professores, mas especificamente no Ensino Fundamental eu tive professores fantásticos, que fizeram várias experiências, vários relatos do dia-a-dia, eles pediam para observar porções com girinos, e eu ficava extasiado com isso, e aos poucos isso foi uma construção.

Outras relevâncias quanto a essa consideração podem ser constatadas nos trechos destacados dos discursos de outros bolsistas (BII e BIII) entrevistados:

\section{Quadro 3: Resposta dos bolsistas sobre a escolha da área de formação. Fonte: Dados da Pesquisa}

BII - [...] Eu estudei em escola voltada para área de agricultura mesmo, [...] é um local que tem muita interação entre os professores e os alunos... e eu me identifiquei muito com os professores de Biologia e da parte de agricultura... a gente ia muito para o campo. E no Ensino Médio, [...] tinha um professor de Biologia muito legal também.... e foi por isso, eu acabei gostando muito dessa área $[\ldots]$

BIII - [...] os professores eram efetivos, pelo menos das matérias principais eram... na Língua Portuguesa, Física, Biologia, inclusive a professora de Biologia era muito boa [...]. Foi... assim..., desde o Ensino Fundamental eu sempre tive afinidade, além da matéria, com os professores, também. Aí eu vi que era uma convivência legal das disciplinas com os professores, e eu fui tomando gosto.

Observamos nos trechos acima o quanto a motivação dos entrevistados pela ciência, nesse caso, pela Biologia, ainda, no Ensino Básico, e o seu contato com docentes, dessa área do conhecimento, foi capaz de lhes promover um ensino significativo das disciplinas curriculares Ciências e Biologia, no Ensino Fundamental e Médio, sendo de relevante importância para a sua decisão sobre uma formação superior que estivesse vinculada a essas vivências experimentadas.

Somos, assim, acometidos dos seguintes questionamentos: Estariam as disciplinas curriculares das Ciências da Natureza assumindo esse caráter motivador na formação de futuras gerações aguçadas pela ciência? As Ciências e a Biologia, disciplinas curriculares, respectivamente, no Ensino Fundamental e Médio, cumprem 
com essa missão transformadora de estímulo e produção de um conhecimento significativo dos seus alunos pela ciência?

Schön (1992), no seu texto 'Formar professores como profissionais reflexivos', nos chama a atenção, ao citar Michael Polany, sobre a importância da valorização dos professores pelo "conhecimento tácito", espontâneo, intuitivo, experimental e cotidiano, revelado pelos alunos, nos mostrando que algumas características são peculiares ao professor que queira se apropriar dessa forma de ensinar, buscando nos seus alunos ouvi-los, surpreender-se com eles, dar-lhes atenção e ser curiosos sobre suas inquietações. Para ele, "Esse tipo de ensino é uma forma de reflexão-naação que exige do professor uma capacidade de individualizar, isto é, de prestar atenção a um aluno, mesmo numa turma de trinta, tendo a noção do grau de compreensão e das suas dificuldades" (SCHÖN, 1992, p. 82).

Quanto aos seus interesses pela licenciatura, encontramos no discurso de alguns discentes entrevistados que sua opção pelo curso de licenciatura em Ciências Biológicas se deu sem a real visão da missão que tem esses cursos, quanto à formação docente, algo que pode ser constatado nos trechos em destaque, dos BII, BIII e BVI:

Quadro 4: Resposta dos bolsistas sobre o interesse na licenciatura. Fonte: Dados da Pesquisa

Bll - [...] entrei no curso sem saber ao certo o que era fazer o curso de licenciatura [...] na verdade eu não tinha interesse em ser professor ou pesquisador, o interesse era fazer Biologia e acabou. BIII - [...] Aliás, a licenciatura era assim, o curso Ciências Biológicas, licenciatura era o a mais, não o contrário. Ai eu pensava, eu vou terminar a faculdade e ver, o que der deu, eu não tinha noção de que eu queria ser professor (a) na área e de como ia ser, eu entrei com a cara e a coragem. VII - [...] no começo eu não tinha ideia do que eu tava fazendo. Eu não tinha noção do que era a licenciatura.

Essas constatações nos alertaram sobre outras questões importantes: Que caminhos os cursos de licenciatura devem se propor ao pensarem a formação desses 
discentes? E que políticas de valorização do magistério devem ser planejadas para a motivação dessas futuras gerações de professores de Ciências em relação à carreira docente de forma lúcida quanto às proposições dos cursos de licenciatura?

Na busca de resposta a essas perguntas, corroboramos com Nóvoa (1992) quando afirma que "a formação deve estimular uma perspectiva crítico-reflexiva, que forneça aos professores os meios de um pensamento autônomo e que facilite as dinâmicas de auto-formação participada", onde, para esse autor, estar em formação implicará "[...] (re)encontrar espaços de interação entre as dimensões pessoais e profissionais, permitindo aos professores apropriar-se dos seus processos de formação e dar-lhes um sentindo no quadro das suas histórias de vida" (NÓvOA, 1992, p. 13).

Proposição II. Os licenciandos bolsistas não possuem boas impressões sobre a escola de Ensino Básico pública e a carreira docente, o que interfere diretamente no seu interesse em atuarem como futuros professores do Ensino Básico.

Antes de qualquer consideração, vale ressaltar que os sujeitos entrevistados tiveram, quando não durante toda a sua formação nos Anos Iniciais e Finais na escola formal, mas, pelo menos, em algum momento, o contato com o Ensino Básico público, apresentando, nos seus discursos, impressões nem sempre positivas sobre suas escolas e o ensino que lhe fora oferecido.

Esse fato é evidenciado, quando, por exemplo, relatam suas frustrações, a decepção com o Ensino Médio, quanto à um momento crucial na vida dos jovens, do período regular de ensino, no que se refere às suas escolhas profissionais, como demonstrado abaixo nos discursos do BVI e BVII: 
Quadro 5: Resposta dos bolsistas sobre o interesse na licenciatura. Fonte: Dados da Pesquisa

BVI - [...] No terceiro ano onde eu achei que talvez eu fosse mais orientado (a), onde eu esperava isso, não foi bom não. Os professores mesmo falavam: "ah, gente, tenta algo mais próximo, aqui perto" - até particular mesmo eles diziam. E esse mundo de federal eu só fui me envolver depois que eu saí da minha cidade.

BVII - [...] Eu não tive um dos melhores não. Mas eu tive assim, alguns professores muito bons e outros, também, muito ruins. É, e assim, eu consegui tudo que eu tenho hoje, foi por mim, foi por lutar, correr atrás, pois a escola pública tá muito precário. São raros os professores que querem que o aluno realmente aprenda e que querem que o aluno saia dali e curse uma faculdade. Eles não levam muito esse interesse para os alunos [...]

Essa é uma etapa de tomadas de decisões importantes para qualquer ser humano, na sociedade neoliberal do mundo contemporâneo, que entendemos, na sua conjuntura, não é capaz de promover condições políticas e sociais adequadas, igualitárias e humanistas de promoção dos indivíduos da sociedade em detrimentos aos interesses capitais, onde a "socialização do homem é condição primordial para a superação do capitalismo" (GADOTTI, 1997).

Caem, assim, em contradição muitas escolas, ao percebemos o quão despreparadas estão na missão que deveriam exercer, por não se encontrarem como reais agentes transformadores dos indivíduos à elas submetidos, promovendoos nas suas potencialidades, instigando-os na busca de se tornarem sujeitos autônomos nas suas escolhas.

Nessa perspectiva, entendemos o ambiente escolar como um espaço de reflexão, numa cumplicidade das ideias sobre o que seria uma escola reflexiva sobre sua prática, vislumbrando-o como uma "[...] organização (escolar) que continuamente se pensa a si própria na sua missão social e na sua organização, e se confronta com o desenrolar da sua atividade em um processo heurístico simultaneamente avaliativo e formativo" (ALARCÃO, 2001, p. 25). 
Porém, entendemos que essa é uma discussão que ultrapassa os limites dessa pesquisa, solicitando um aprofundamento nas raízes históricas sociais e políticas, por exemplos, da construção do perfil da educação pública nacional, que talvez nos ofereçam os subsídios para entendermos esses descaminhos.

Atrelado a isso, vale frisar em relação ao discurso dos bolsistas BI, BII, BIV, BV e BVII, suas avaliações sobre a situação da carreira do professor no Brasil, as condições salariais e os recursos técnico-funcionais para uma atuação eficiente desse profissional nas escolas públicas, quando questionados sobre o que consideram desmotivadores quando pensam em ingressar na carreira de docente:

\section{Quadro 6: Resposta dos bolsistas sobre o que desmotiva na licenciatura. Fonte: Dados da Pesquisa}

BI - [...] Ah, o salário e a desvalorização do professor, dentre outras coisas.

BII - [...] a questão financeira pesa né, eu gosto muito de estar em sala de aula, mas pensando por um lado eu vou ganhar pouco, então, vou ter que ter uma carga horária bem maior, um trabalho bem grande, mas isso não é uma questão desmotivadora, a questão financeira em si, o que mais me desmotiva é o ambiente de trabalho, a gestão, os demais professores...

BIV - [...] O medo de enfrentar uma sala com trinta alunos [...] alunos, com quarenta e cinco alunos, independente do número de alunos, o medo de chegar aqui na frente e dizer EU VOU DAR AULA (entonação forte com pausa longa)... eu sou estudante ainda (ênfase), eu entro em desespero quando eu tenho que apresentar um seminário da coisa mais simples, apesar de que para quem se aplica os seminários... o meu professor entende da área, na aula de Ciências, as outras trinta não entendem... eu seria a entendedora da disciplina e isso ainda me assusta (outra pausa longa)... Como é que eu vou lidar com uma turma de trinta e cinco alunos para passar um conteúdo. Uma coisa é eu juntar trinta e cinco pessoas e fazer um bate papo sobre Biologia, fazer uma entrevista, outra bem diferente é eu manter trinta e cinco alunos sentados, quietos para eu ensinar um conteúdo que é de prática dele, que é do cotidiano deles, independente se seja de primeira à quarta ou de quinta à oitava, e não é só por causa dos alunos com dificuldades, ou transtorno qualquer... eu tenho que dar o conteúdo, eu tenho que entender que aquele aluno que não tá prestando atenção é de classe média baixa, ele não almoçou, não jantou ou ele tá ali inquieto por que ele não tem como se concentrar.

BV - [...] Acho que falta de tempo de planejamento, eu vejo muitos professores reclamando. É muita carga horária dentro dá sala de aula e pouco para planejar.

BVII - [...] [...] a gente sai da Universidade a todo vapor, cheio de coisas novas, de ideias, mas quando a gente ingressa numa escola a gente é extremamente podado. É muito difícil você chegar numa escola onde você tem " $n$ " ideias e dessas " $n$ " ideias você não vai conseguir fazer nem um terço delas. Você tem que se adequar a um sistema. Entendeu? 
Os (as) bolsistas apresentam nos seus discursos indignações quanto ao salário e às jornadas de trabalho advindas dessa realidade, porém, não consideram esse um fator implicador para não seguirem a carreira docente, sendo as superlotações das salas de aula, a falta de tempo fora delas para o devido planejamento das aula, a sujeições à situações que consideram escusas, como a aprovação sem o real aprendizado e as dificuldades geradas por gestões não participativas do processo como um todo das escolas, como sendo os principais fatores desmotivadores, reafirmando a necessidade prioritária de transformação dessa categoria profissional, quanto "[...] à mudança no reconhecimento social da importância do trabalho docente, às condições materiais das Escolas e aos salários dos professores" (HERNÁNDEZ, 1998, p. 09).

Porém, identificamos, também, que tal situação, retomando o ponto inicial da discussão nessa análise, muitas vezes, superou-se pela ação diferenciada de professores que se sobressaíram dentre as adversidades que cada realidade impunha. Destacam os (as) bolsistas BIII e BIV, por exemplo, maior satisfação com seu tempo de alunos no Ensino Fundamental, em relação ao Ensino Médio, de forma a constatarmos que, é importante darmos a devida atenção aos tempos escolares desse seguimento de ensino:

Quadro 7: Resposta dos bolsistas sobre o ensino fundamental. Fonte: Dados da Pesquisa

BIII - [...] A escola de quinta à oitava série me deu bastante base para a vida em geral, não só em sala de aula.

BIV - [...] Durante o Ensino Fundamental, até a oitava série... eu fiz escola pública municipal... [...] Eu sempre tive professores que estavam preocupados com a subjetividade do aluno [...]

Assim, novamente, emergem questões importantes sobre essas realidades: Em que se diferenciam desses contextos educacionais deturpados, das escolas capazes de se superarem nas expectativas dos seus alunos, na sua capacidade de promovê- 


\section{D|EDebates

los a sujeitos donos do seu tempo, da sua história? Em que rumos, as atuais gerações, seguirão em relação à carreira docente e como podem interferir as políticas públicas de formação docente nesses contextos do Ensino de Ciências, nos Anos Finais do Ensino Fundamental?

Apoiamo-nos na concepção de que ensinar vai além de se transferir conteúdos e que formar ultrapassa a condição criadora de forjar corpos inertes, exigindo-se, então, identificar na Educação que ela se efetiva de forma que "não há docência sem discência, as duas se explicam e seus sujeitos apesar das diferenças que os conotam, não se reduzem à condição de objeto, um do outro" (FREIRE, 2006, p. 25), concebendo a escola "[...] comoum local, um tempo e um contexto educativo" (ALARCÃO, 2001, p. 16), preparando cidadãos para a vida, mas para além disso, pois, como afirma Alarcão (2001, p. 18) "ela é a própria vida, um local de vivência da cidadania".

Proposição III. O contato dos licenciandos em Ciências Biológicas com o cotidiano das escolas de Ensino Básico, no Pibid, promoveu implicações significativas sobre seu processo de decisão quanto à carreira docente.

As análises das duas proposições realizadas anteriormente nos subsidiam na interpretação dos dados coletados de onde emerge essa terceira proposição de análise por caracterizar pontos importantes do perfil dos sujeitos dessa pesquisa.

Seus interesses e motivações enquanto acadêmicos do curso de licenciatura plena em Ciências Biológicas, suas percepções quanto vivências como ex-alunos da escola básica e as concepções advindas dessas experiências sobre as contribuições da educação pública e o perfil do professor de Ciências dessas escolas, coletadas e descritas nas entrevistas, criam solo fértil para identificarmos quais foram as implicações do Pibid na formação desses licenciandos bolsistas. 
O incentivar da formação de docentes em nível superior para a Educação Básica, contribuindo para a valorização do magistério como premissa de se elevar a qualidade da formação inicial de professores nos cursos de licenciatura, além de promover a integração entre educação superior e educação básica, são prerrogativas do Pibid. Cabe-nos reafirmarmos que essa é uma política com muitas peculiaridades quanto à formação inicial de professores, que traz como implicadores cuidados no cumprimento de outros pontos importantes, que versam como propostas transformadoras desse Programa.

Falamos, por exemplo, da responsabilidade solicitada às instituições envolvidas no Pibid da sua capacidade para atender a demanda de inserção dos licenciandos bolsistas nos contextos escolares, na intenção de lhes proporcionar vivenciarem (a vivência) do cotidiano das escolas públicas.

Nessa sequência de constatações, outros apontamentos nos solicitam atenção quanto ao objetivo V e VI do Art. 40, Pot. 96/2013, sobre o papel dos professores supervisores como "co-formadores" dos futuros professores do Ensino Básico, esses (as) licenciandos (as) bolsistas, promovendo "por meio da apropriação e da reflexão sobre instrumentos, saberes e peculiaridades do trabalho docente" (BRASIL, 2013), contribuindo na melhoria da qualidade das práticas dos cursos de licenciatura.

Nos perguntamos, então: O quão significativo foi para os sujeitos dessa pesquisa, aturarem como bolsistas do Pibid? Quais foram as implicações advindas desse processo, como colaboraram os professores supervisores envolvidos para essas significações e como interferiram no seu processo de formação e no seu interesse pela carreira docente?

Um fator importante a se ressaltar é de que a bolsa teve peso considerávelno interesse desses (as) licenciandos (as) ingressarem no Pibid, por toda conjuntura que envolviam necessidades pessoais e financeiras, de manutenção durante a sua 
graduação, principalmente por não terem, ainda, nesse período de inserção, visão clara do que se propunha o projeto, algo que foi se esclarecendo ao longo das sua jornada como pibidianos, entendendo essa como a primeira característica inovadora do Pibid, como política pública de formação de professores, quando foi criada uma bolsa específicas para programas de licenciatura. Constatações como essas, sobre as motivações iniciais dos pibidianos em relação à sua adesão ao Programa, também, foram identificadas, por André (2016), numa análise comparativa que faz entre políticas de iniciação à docência, o Pibid, o Bolsa Alfabetização, criado na Bahia, em 2007 e o Bolsa Formação-Aluno-Aprendizagem (BFAA), iniciado em 2010.

Identificamos, nos discursos dos entrevistados (as), com exceção de um (a) bolsista, que todos possuem experiência de atuação pelo Programa tanto no Ensino Médio, como no Ensino Fundamental, a partir do ano de 2010, quando ingressavam como alunos do curso de licenciatura plena em Ciências Biológicas.

Definimos dois momentos de construções das relações desse grupo de bolsistas: primeiro, quanto à sua atuação numa primeira escola, de Ensino Médio, entre os períodos letivos de 2010 e 2011; e segundo, entre os anos de 2012 e 2013, em outra escola de Ensino Fundamental.

Porém, deixaram claro que o período significativo para o seu processo de formação se deu na escola de Ensino Fundamental, a partir da vivência diferenciada, experimentando situações com as quais não haviam, ainda, tido contato nos dois primeiros anos do Programa, como consta das falas dos bolsistas BIII e BVI abaixo citadas: 
Quadro 8: Resposta dos bolsistas sobre o processo de formação. Fonte: Dados da Pesquisa

BIII - [...] no começo a gente só cumpria horário no Pibid.. Só cumpria horário! Isso não me trouxe a experiência que eu tenho hoje aqui (...) (cita a escola de Ensino Fundamental) e nem o gosto pela profissão, por que eu não conhecia nada, só cumpria horário, fazia uma vez ou outra uma atividade, mas coisa muito pouca, então não dava pra ter noção, não dava pra tirar experiência nenhuma [...] até teve algumas experiências legais, mas dentro de dois anos, né? Se for comparar o tempo, foi muito pouco né. Mas lá as coisas funcionavam bem quando a gente ia pra sala, por exemplo, mas aqui nessa escola, a gente tem uma autonomia, tem mais afinidade com os professores com quem a gente trabalha, a gente fazer uma proposta, discutir alguma coisa. É isso! BVI - [...] eu não vou detonar a outra escola. Eu acho que são interesses diferentes, e que tem professores que se sentem mais à vontade ou não com sua presença, ou se sentem meio desconfortável. A gente até tinha um espaço, que era um laboratório, de Biologia, de Ciências. Só que assim, fazíamos pouco, poucas atividades, mas a gente só ia uma vez por semana lá. Até por isso que eu entrei no projeto, porque antes eu achei que seria todo dia. E antes eu saí do meu emprego e eu recebia pouco mais do que quatrocentos reais. Aí eu pensei, "tô vendo o pessoal ir uma vez por semana... ah, eu vou querer também". Aí, quando a escola mudou de lugar nós perdemos o lugar, e ai nós ficávamos mais na biblioteca cumprindo horário.

Cabe esclarecer que durante o período em que aturam no Ensino Médio, os licenciandos bolsistas acompanharam um processo de migração da escola para um outro prédio locado para sua sede, devido à reconstrução de uma nova escola aprovada pelo governo do Estado do Espírito Santo - referente ao trecho no qual o (a) bolsista VI cita "[...] quando a escola mudou de lugar".

Encontramos nessas falas os indícios de frustrações desse grupo de licenciandos com a experiência que tiveram no Programa durante o período em que atuaram no Ensino Médio. Essas são frustrações constatadas, também, nos diálogos entre pibidianos, supervisores e coordenadores do Pibid-Ufes de Alegre e Vitória, durante uma mesa redonda no "I Encontro do PibidUfes", realizado no mês de Novembro de 2013, quando relatam das suas experiências nas primeiras empreitadas de implantação e desenvolvimento dos subprojetos nas escolas públicas desses municípios, não cabendo julgamentos aleatórios que suscitem responsabilidades sobre, apriori, o que seria caracterizado como fracasso, mas que 
motivem pesquisas sobre como essas relações foram instituídas e de que forma podem ser repensadas.

Consideramos, para análise do processo não os fragmentos isolados no espaço-tempo, mas, o conjunto de experiências vivenciadas por esses pibidianos e os outros atores aí envolvidos como um ciclo importante de aprendizados, remetidos por eles, que nos conduz a uma visão de novas diretrizes que possam contribuir efetivamente para a formação inicial dos futuros professores de Ciências, para o Ensino Básico no Pibid.

Percebeu-se na fala dos entrevistados BI e BIV, que a identificação com a prática do professor supervisor foi de fundamental importância para implicações de relevância para sua motivação como pibidianos, no período investigado:

\section{Quadro 9: Resposta dos bolsistas sobre o processo de formação. Fonte: Dados da Pesquisa}

BI - [...]Começou com a escolha do nosso coordenador, ele deu uma palestra pra gente, todos nós ficamos vislumbrados, apaixonados pelo tema, pela didática dele e decidimos vir pra cá. A partir da acolhida do nosso coordenador, ficou tudo mais fácil, de trabalhar e de se realizar... ao contrário da frustração com o primeiro trabalho... foi dez! [...] ele tem que ser o líder, o carro chefe, e fazer a coisa funcionar como deve ser, como deve funcionar.

BVI - [...] Com os professores supervisores do PIBID na... (citou a escola de Ensino Fundamental), nós tivemos um retorno muito melhor da nossa coordenadora, por eles entrarem em contato com ela, solicitando, mandando e-mail. Isso fez com que ela nos procurasse mais, e nós tivéssemos mais próximos dela do que antes, interessando-se pela didática que a gente desenvolvia, as práticas, cobrando mais da gente, como presença, nos reunindo até três vezes por mês. Surtindo como um efeito positivo, então. O legal é que os professores supervisores aqui não mandam somente, mas querem saber como aconteceu a atividade, como ocorreu e em dúvidas entram em contato com o coordenador e se tiver algo errado a gente toma dois esporros (risos e descontração) [...] Assim, se não fosse o professor supervisor, não poderia existir esse Programa, o Pibid.

Identificamos na fala de um (a) bolsista, traços de criticidade quanto à escolha das escolas onde serão implementados os subprojetos: 
Quadro 10: Resposta dos bolsistas sobre as esolas escolhidas. Fonte: Dados da Pesquisa

BI - [...] Eu aprendi muitas coisas aqui, tem muitas diferenças mesmo, e eu acho que o projeto deveria fazer uma seleção. Investigar a escola, como que é, e ver se a escola está realmente apta a receber à gente.

Quando o (a) bolsista diz "Eu aprendi", traz à tona convicções sobre o que teve significado para ele (a), sendo capaz de refletir sobre suas vivências e criticar, também, a prática do outro na busca de novos direcionamentos para o processo no qual está envolvido.

Nessa condição, assinalamos implicações positivas do Programa quanto às concepções desses licenciandos no que diz respeito à sua carreira docente, de futuros professores de Ciências, no Ensino Básico, caracterizadas nos seguintes recortes das entrevistas concedidas pelos bolsistas BI, BII e BVII:

\section{Quadro 11: Resposta dos bolsistas sobre as implicações positivas do PIBID. Fonte: Dados da Pesquisa}

BI - [...] A partir do momento em que o Pibid nos proporcionou estar vindo à escola, desde o início da graduação, já foi possivvel a gente conhecer a realidade e ver se é isso mesmo que a gente quer. Quem não quer mesmo, daqui pra lá, vai partir pra outros caminhos. Acho que assim, se fossemos esperar para ter essa experiência no final da graduação, com o estágio obrigatório, muitos colegas poderiam estar frustrados. [...] enxergar a educação de Ciências como um todo, numa visão holística, onde nós temos que pensar não só no conteúdo que o menino tem que ver, mas na realidade do menino, pois as vezes ele tá com fome na sala de aula e não tá conseguindo aprender... ele tem uma dificuldade de aprendizado em alguma matéria que exige mais raciocínio lógico... e experiência aqui nos levou à isso.

Bll - [...] eu passei a ter vontade de ser professor (a) depois que eu passei à atuar no Ensino Fundamental, por que antes eu já queria partir pra pesquisa de campo e aí eu comecei a atuar aqui no Pibid e gostei muito mais de ficar em sala de aula do que no Ensino Médio. Agora eu não tenho mais medo da sala de aula, tipo "Ah, vou acabar a faculdade eu vou fazer o que?" Ah, ser professor pra mim vai ser de boa.

BVII - [...] a gente vivencia várias coisas todos os dias, lida com várias pessoas diferentes, pega uma coisinha boa de um, o que é e o que não é legal a gente diz "não vamos fazer isso não, que isso não é legal", isso vai ajudando a gente a criar nossa identidade dentro do Pibid [...] ser um bom profissional, de tentar errar menos quando a gente estiver na profissão, por que a gente já está cometendo certos erros aqui. 
Assim, quando perguntados sobre qual deve ser o perfil do professor de Ciências, do Ensino Básico, os (as) bolsistas responderam que:

\section{Quadro 12: Resposta dos bolsistas sobre o perfil do professor de ciências. Fonte: Dados da Pesquisa}

BI - [...] A primeira coisa é gostar do que faz, ter paixão, que depois que a gente conhece a realidade a gente vê que não é fácil, que apesar da falta de valorização e tudo mais...

BII - [...] o professor de Ciências em geral, eu acho que tem que ser um professor que explora a parte teórica, mas falta mais experimentação, coisas como projetos... mesmo... montar experiências com os alunos, que eles passem a desenvolver e não o professor que dá tudo para eles.

BIII - [...] O professor de Biologia tem que mostrar conhecimento... é uma matéria bem ampla... até por que no Ensino Fundamental pega Química e Física. E ele tem que motivar o aluno a querer conhecer também o meio onde ele vive... você tem que fazer o aluno se interessar pela ciência, pelo meio em que vive. Eu acho que ele tem que ser, além de tudo, um investigador, porque nada como uma novidade para realçar a curiosidade, a empolgação dos alunos. Então, se ele tem isso para ele e vai conseguir passar...

BIV - [...] aquele professor que não vai simplesmente chegar no quadro e dizer o conteúdo para o aluno, eu vou trazer a realidade do aluno para dentro da sala de aula e fazer que ele entenda que o que ele está estudando ali acontece no dia-a-dia dele [...]

BV - [...] ele deve buscar mais a realidade do aluno, porque, como eu estudava a noite no Ensino Médio, e a maioria dos alunos trabalhava de dia, aí eles já chegavam à noite já cansados, aí eles falavam assim, hoje é sexta-feira, vamos acabar a aula mais cedo. O professor mesmo que não dava aula, ele já ia pensando em não dar aula (risos) para acabar mais cedo. Era essa a realidade. Então, eles achavam que pelo pessoal trabalhar eles achavam que não tinha necessidade de se dar o conteúdo, entendeu? Acho que o perfil deve ser esse, não pesar tanto com o conteúdo, mas....ah, não sei se você vai entender...(risos)

BVI - [...] tem que tentar aproximar o máximo da realidade, do dia-a-dia da pessoa, oferecendo mais aulas práticas, desenvolver mais isso, questões de... ah, fugir mais da rotina.

BVII - [...] Eu acho que tem que ser um professor que sempre procure inovar em suas aulas [...] tem que conhecer a singularidade de cada aluno [...] o professor de ciências tem que trazer além dessas coisas lúdicas, trazer, também, coisas além do livro didático [...] aumentar esse suporte para o aluno[...] A partir do momento em que os alunos veem esse interesse, que o professor quer que eles aprendam.

Para esses (as) bolsistas é importante, antes de mais nada, que haja identificação por parte do professor de Ciências com a carreira docente, e, então, que seja motivador para os alunos pelos temas científicos a partir de experimentações por meio de práticas investigativas, sendo inovador, com constante 
preocupação com a contextualização dos conteúdos curriculares apresentados, percebendo isso, principalmente nos trechos destacados nas falas citadas, onde o termo "realidade do aluno" aparece como uma grande preocupação da responsabilidade que deve ter o professor de Ciências.

Identificamos que essas são considerações que surgem na (re)contrução das suas concepções sobre a profissão docente, a partir das suas vivências no Pibid, durante o período em que tiveram contato com a escola de Ensino Fundamental, onde foi fomentado o Programa.

\section{CONSIDERAÇÕES FINAIS}

A partir da análise desenvolvida dos discursos dos pibidianos sujeitos, destacamos que é urgente a necessidade de repensarmos a formação inicial de professores de Ciências, na busca da construção de perfis conscientes desses profissionais sobre seu papel como agentes transformadores dos espaços escolares num constante processo de reflexão-crítica (NÓVOA, 1992) sobre os saberes construídos nas relações do processo ensino-aprendizagem nessas disciplina curricular, como apontado por Carvalho e Gil-Pérez (2011) e também por Marandino e Krasilchik (2007), contribuindo para o interesse das novas gerações pela carreira docente, constatações claras a partir do desenvolvimento da proposição I, que nos direcionou sobre a importância dos tempos escolares na Educação Básica quanto ao desenvolvimento do interesse pela ciência pelo contato dos discente com professores que entendem a escola como um espaço para o desenvolvimento humano, cultural, social e econômico (ALARCÃO, 2001).

Desvelamentos de possíveis respostas às questões emergentes, que foram suscitadas a partir das proposições II e III, surgiram quando dentre os objetivos traçados pelo Pibid, identificamos, nas experiências vivenciadas pelos sujeitos 
entrevistados, esse Programa como a possibilidade de "contribuir para que os estudantes de licenciatura se insiram na cultura escolar do magistério, por meio da apropriação e da reflexão sobre instrumentos, saberes peculiares do trabalho docente" (BRASIL, 2013), promovendo aproximações dos discentes com o cotidiano escolar, num processo de clarificações para os sujeitos dessa investigação,outras dimensões da Educação, na ação política de transformação desses discentes, como agentes ativos e questionadores, capazes de, criticamente, reivindicarem espaços e condições melhores como futuros profissionais da Educação.

Por fim, as colocações dos (as) bolsistas, demonstraram ressignificações que corroboram com uma formação emancipadora solicitada por Freire (2006), desses futuros professores de Ciências, do Ensino Básico, quando evidenciam a importância de conhecer a realidade do cotidiano escolar, entendendo o ensino de Ciências com uma visão holística (HERNÁNDEZ, 1998; MORIN, 2007), descobrindo suas aptidões profissionais e identificando-se com o processo ensino-aprendizagem, percebendo a necessidade de refletir e criticar sua prática diária (SCHÖN, 1992; NÓVOA, 1992; ALARCÃO, 1996, 2001, 2011; FREIRE 2006), de forma a considerarmos o Pibid como um Programa que aponta, nesse contexto complexo da formação inicial, caminhos possíveis para a construção, então, de perfis reflexivos e críticos do futuro professor de Ciências na Educação Básica, porém, identificamos que é na proposta amparada na Portaria № 96 de julho de 2013, que regia esse Programa até o primeiro semestre do ano de 2016, em detrimento à proposta atualmente vigente, que esse Programa apresenta prerrogativas viáveis e possíveis de uma política de formação inicial de professores emancipadora, o que nos faz apontar a necessidade de outras pesquisas nesse campo. 


\section{REFERÊNCIAS}

ALARCÃO, I. Reflexão crítica sobre o pensamento de D. Schön e os programas de formação de professores. Revista da Faculdade de Educação - USP. v. 22, n. 2 (1996). Disponível em: <http://www.revistas.usp.br/rfe/article/view/33577>. Ultimo acesso em: 30 ag. 2016.

ALARCÃO, I. (Org.). Escola reflexiva e nova racionalidade. Porto Alegre: ARTMED, 2001.

ALARCÃO, I. Professores Reflexivos numa Escola Reflexiva. 8. ed. São Paulo: Cortez. 2011.

ANDRÉ, M. Políticas de Iniciação à docência para uma formação profissional qualificada. In. (Org.) ANDRÉ, M. Práticas inovadoras na formação de professores. Campinas: Papirus, 2016.

ASTOLFI, J.; DEVELAY, M. A didática das Ciências.16. ed. Campinas, SP: Papirus, 2012. BRASIL. Secretaria de Educação Fundamental. Parâmetros curriculares nacionais: Ciências naturais. Brasília: MEC/SEF, 1998. Disponível em:

$<$ http://portal.mec.gov.br/seb/arquivos/pdf/ciencias.pdf>. Último acesso em: 01 jun. 2016.

BRASIL. Portaria Normativa no 38, de 12 de dezembro de 2007a.Dispõe sobre o Programa Institucional de Bolsa de Iniciação à Docência - PIBID. Diário Oficial da União, n. 239, seção 1, p. 39, 2007.

BRASIL. Ministério da Educação. Seleção pública de propostas de projetos de iniciação à docência voltados ao Programa Institucional de Bolsa de Iniciação à Docência (PIBID). Edital MEC/CAPES/FNDE. 12 dez. 2007b. 8p. 
BRASIL. Portaria Normativa № 72, de 9 de abril de 2010. Dá nova redação a Portaria que dispõe sobre o Programa Institucional de Bolsa de Iniciação à Docência - PIBID, no âmbito da CAPES. Diário Oficial da União, n. 68, seção 1, p. 26-27, 2010.

BRASIL. Portaria Normativa no 096, de 18 de julho de 2013. Dispõe sobre regulamento do Programa Institucional de Bolsa de Iniciação à docência. Acessado em 23 ag. 2016. Disponível em:<https://www.capes.gov.br/images/stories/download/legislacao/Portaria_096_1 8jul13_AprovaRegulamentoPIBID.pdf>. Último acesso em: 23 ag. 2016. BRASIL. Portaria Normativa no 46, de 11 de abril de 2016. Aprova o Regulamento do Programa Institucional de Bolsa de Iniciação à Docência - Pibid. Disponível em: <https://www.capes.gov.br/images/stories/download/legislacao/15042016-Portaria46-Regulamento-PIBID-completa.pdf>. Último acesso em: 23 de ag. 2016.

BELEl, Renata A., et. al. O uso de entrevistas, observação e videogravação em pesquisa qualitativa. Cadernos de Educação. FaE/PPGE/UFPel. Pelotas, RS: 187-199, janeiro/junho 2008. Acesso em 18 de dezembro de 2013. Diponível em:

<http://www.periodicos.ufpel.edu.br/ojs2/index.php/caduc/article/viewFile/1770/16 45>. Último acesso em: 30 ag. 2016.

CARVALHO, A. M. P.; GIL-PÉREZ, D. Formação de professores de ciências: tendências e inovações. 10. Ed. São Paulo: Cortez, 2011. (Questões da nossa época; v. 28)

DUARTE, R. Entrevistas em pesquisas qualitativas. Educar, Curitiba, n. 24, p. 213-225, 2004. Editora UFPR.

ESPÍRITO SANTO. Programa Institucional de Bolsa de Iniciação à Docência - PIBID. Detalhamento do Subprojeto de Licenciatura em Ciências Biológicas do Centro Universitário Norte do Espírito Santo - CEUNES/UFES. 2009.10p. 


\section{E Debates \\ em Educação Cientifica e Tecnológica

FREIRE, P. Pedagogia da autonomia: saberes necessários à prática educativa. 33. ed. São Paulo: Paz e Terra, 2006. 148 p.

FREIRE, P. Pedagogia do oprimido. 46. ed. Rio de Janeiro: Paz e Terra, 2007. 213 p. GADOTTI, M. Concepção dialética da educação: um estudo introdutório.10. ed. São Paulo: Cortez, 1997.

GONÇALVES, E. N. C.; COMARU, M. W. Contribuições da pedagogia de projetos na Construção do perfil reflexivo-crítico de futuros Professores de ciências no pibid. X ENCONTRO NACIONAL DE PESQUISA EM EDUCAÇÃO EM CIÊNCIAS: X ENPEC. Águas de Lindóia; 24 a 27 de Novembro de 2015. Disponível em:

<http://www.xenpec.com.br/anais2015/resumos/R1487-1.PDF>. Último acesso em: 30 ag. 2016.

HERNANDEZ, F.; VENTURA, M. A organização do currículo por projetos de trabalho. Porto Alegre: Artmed, 1998.

HERNANDEZ, F. Transgressão e Mudança na Educação: Os Projetos de Trabalho. Porto Alegre: Artmed, 1998.

LÜDKE, M.; ANDRÉ, M. E. D. A. Pesquisa em educação: abordagens qualitativas. Ed. 1. São Paulo: EPU, 1986.

MIGUEL, F. V. C. A entrevista como instrumento para investigação em pesquisas qualitativas no campo da linguística aplicada. Revista Odisseia - PpgEL / UFRN. № 5 [jan-jun 2010] ISSN 1983-2435. Consultado em 28 de dezembro de 2013. Disponível em: <http://www.periodicos.ufrn.br/odisseia/article/download/2029/1464>. Último acesso em: 30 ag. 2016.

MIZUKAMI, Maria da Graça Nicolletti. A escola e a aprendizagem da docência: processos de investigação e formação. 2. Ed. São Carlos: EdUFSCar, 2010. 


\section{D|EDebates

MORAES, R.Uma tempestade de luz: a compreensão possibilitada pela análise textual discursiva. Ciência \& Educação, v. 9, n. 2, p. 191-211, 2003. Disponível em: <http://www.scielo.br/pdf/ciedu/v9n2/04.pdf>. Último acesso em: 30 ag. 2016. MORAES, R.; GALIAZZI, M. C. Análise textual discursiva: processo reconstrutivo de múltiplas faces. Ciência \& Educação, v. 12, n. 1, p. 117-128, 2006. Disponível em: <http://www.scielo.br/pdf/ciedu/v12n1/08.pdf>. Último acesso em: 30 ag. 2016. MORAES, R.; GALIAZZI, M. C. Análise textual discursiva. 2. Ed. rev. Ijuí: Unijuí, 2013. (Coleção educação em ciências).

MORIN, E. A cabeça bem-feita: repensar a reforma, reformar o pensamento. Tradução de Eloá Jacobina. 13ạ ed. - Rio de Janeiro: Bertand Brasil, 2007.

NASCIMENTO, F.; FERNANDES, H. L.; MENDONÇA, V. M. O ensino de ciências no Brasil: história, formação de professores e desafios atuais. Revista História, Sociedade e Educação no Brasil, 39, p. 225-249, 2010. Disponível em: <http://www.histedbr.fae.unicamp.br/revista/edicoes/39/art14_39.pdf>. Último acesso em: 30 ag. 2016.

NOVOA, A. Formação de professores e profissão docente. In: António Nóvoa (coordenação). Os professores e a sua formação. Lisboa: Publicações Dom Quixote, 1992, p.13-33. Disponível em:

<http://repositorio.ul.pt/bitstream/10451/4758/1/FPPD_A_Novoa.pdf>. Último acesso em: 25 ag. 2016

PEREIRA, J. E. D. Formação de professores - pesquisa, representações e poder. 2. ed. 1. reimp. Belo Horizonte: Autêntica, 2007. 167 p.

PIMENTA, Selma G. Professor reflexivo: construindo uma crítica. In. PIMENTA, Selma Garrido; GHEDIN, Evandro (Orgs.) Professor reflexivo no Brasil - gênese e crítica de um conceito. 2. Ed. São Paulo: Cortez, 2002. 


\section{E Debates

SCHÖN, D. A. Educando o profissional reflexivo: um novo design para o ensino e a aprendizagem. Porto Alegre, Rio Grande do Sul: Artmed, 2000.

SCHÖN, D. A. (1988). Formar professores como profissionais reflexivos. In A. Nóvoa (Coord.) (1992). Os professores e a sua formação.Lisboa, Dom Quixote e IIE. Disponível em: <http://profmarcusribeiro.com.br/wpcontent/uploads/2012/04/Formar-Professores-como-Profissionais-Reflexivosdonald-schon.pdf>. Último acesso em: 25 ag. 2016.

SILVA, M. A. J. Aimplementação do programa institucional de bolsas de iniciação à docência UFES/SEDU-ES: por uma nova educação científica. XXIV SIMPÓSIO BRASILEIRO DE POLÍTICA E ADMINISTRAÇÃO DA EDUCAÇÃO E III CONGRESSO INTERAMERICANO DE POLÍTICA E ADMINISTRAÇÃO DA EDUCAÇÃO. Universidade Federal do Espírito Santo - Vitória: 2009. Disponível em:

<http://www.anpae.org.br/congressos_antigos/simposio2009/256.pdf>. Último acesso em: 20 jul. 2016.

WELLER, W.; PFAFF, N. Metodologias da pesquisa qualitativa em educação: teoria e prática. Ed. 2. Petrópolis, RJ: Vozes, 2011.

ZEICHNER, K. M. A formação reflexiva de professores: idéias e práticas. Lisboa, EDUCA. 1993.

Recebido em: Outubro de 2017. Publicado em: Dezembro de 2017. 